\title{
Therapeutic hypothermia in patients with coagulopathy following severe traumatic brain injury
}

Toru Hifumi ${ }^{1,6^{*}}$, Yasuhiro Kuroda', Kenya Kawakita', Susumu Yamashita' ${ }^{1}$, Yasutaka Oda ${ }^{3}$, Kenji Dohi ${ }^{4}$, Tsuyoshi Maekawa ${ }^{5}$ and on behalf of the Brain Hypothermia (B-HYPO) study group in Japan

\begin{abstract}
Background: Coagulopathy in traumatic brain injury (TBI) has been associated with poor neurological outcomes and higher in-hospital mortality. In general principle of trauma management, hypothermia should be prevented as it directly worsens coagulopathy. Therefore, we examined the safety of mild therapeutic hypothermia (MTH) in patients with coagulopathy following severe TBI.
\end{abstract}

Methods: We re-evaluated the brain hypothermia (B-HYPO) study data based on coagulopathy and compared the Glasgow Outcome Scale scores and survival rates at 6 months using per protocol analyses. Coagulopathy was defined as an activated partial thromboplastin time (APTT) $>60 \mathrm{~s}$ and/or fibrin/fibrinogen degradation product levels (FDP) $>90 \mu \mathrm{g} / \mathrm{mL}$ on admission. Baseline characteristics, coagulation parameters, and outcomes were compared between the control and MTH groups with or without coagulopathy.

Results: In patients with coagulopathy, 12 patients were allocated to the control group $\left(35.5-37.0^{\circ} \mathrm{C}\right)$ and 20 patients to the MTH group $\left(32-34^{\circ} \mathrm{C}\right)$. In patients without coagulopathy, 28 were allocated to the control group and 59 patients were allocated to the MTH group.

In patients with coagulopathy, favorable neurological outcomes and survival rates were comparable between the control and MTH groups (33.3\% vs. $35.0 \%, P=1.00 ; 50.0 \%$ vs. $60.0 \%, P=0.72$ ) with no difference in complication rates. On admission, no significant differences in APTT or FDP levels were observed between the two groups; however, APTT was significantly prolonged in the MTH group compared to the control group on day 3.

Discussion: Based on our study, MTH did not seem to negatively affect the outcomes in patients with coagulopathy following severe TBI on admission; therefore, the present study indicates that MTH may be applicable even in patients with severe TBI and coagulopathy.

Conclusions: Our study suggests that in comparison to control, MTH does not worsen the outcome of patients with coagulopathy following severe TBI.

Trial registration: UMIN-CTR, No. C000000231, Registered 13 September 2005.

Keywords: Coagulopathy, Therapeutic hypothermia, Traumatic brain injury, Targeted temperature management, Fibrinogen degradation products

\footnotetext{
* Correspondence: hifumitoru@gmail.com

${ }^{1}$ Department of Emergency, Disaster and Critical Care Medicine, Kagawa

University Hospital, 1750-1 Ikenobe, Miki, Kita, Kagawa 761-0793, Japan

${ }^{6}$ Department of Emergency, Disaster and Critical Care Medicine, 1750-1

Ikenobe, Miki, Kita, Kagawa 761-0793, Japan

Full list of author information is available at the end of the article
} 


\section{Background}

Coagulopathy in traumatic brain injury (TBI) has been associated with poor neurological outcomes and higher in-hospital mortality [1-5]. However, in previous studies, the reported incidence of coagulopathy in isolated TBI patients has varied from $7 \%$ to $86 \%$ due to the use of differing definitions of coagulopathy $[1,6,7]$.

Recently, a revised lethal triad has been proposed, with coagulopathy (fibrin/fibrinogen degradation products (FDP) levels $>90 \mu \mathrm{g} / \mathrm{mL}$ ) posited to have a central role [8]. As a general principle of trauma management, hypothermia should be prevented as it directly worsens coagulopathy. In vitro studies have demonstrated that hypothermia below $33{ }^{\circ} \mathrm{C}$ can cause coagulation dysfunction; however, the risk of bleeding associated with mild therapeutic hypothermia (MTH) is considered to be relatively small $[9,10]$.

Many randomized clinical trials (RCT) have been conducted to investigate the effectiveness of MTH for TBI, but they could not demonstrate more favourable outcomes than those obtained by normothermia (at $37{ }^{\circ} \mathrm{C}$ ) [11-13]. However, the latest guidelines from an expert panel suggested considering TTM at $34-35{ }^{\circ} \mathrm{C}$ in order to lower ICP in TBI patients with refractory intracranial hypertension despite medical treatments [14]. Furthermore, trials examining efficacy and safety in patients with coagulopathy following TBI are yet to be conducted [11-13, 15, 16]. Therefore, we examined the hypothesis that MTH is harmful in patients with coagulopathy following severe TBI. The purpose of the present study was to examine the effect of coagulopathy on the safety of MTH compared to control in patients with severe TBI.

\section{Methods}

\section{B-HYPO study}

The B-HYPO study was conducted as a prospective, multicenter RCT between December 2002 and September 2008. The protocol was approved by the Institutional Review Board of each participating hospital, and the trial was registered at the University Hospital Medical Information Network site (UMIN-CTR, No. C000000231, Registered 13 September 2005) in Japan and at the National Institutes of Health site (Clinical Trials. Gov, Identifier NCT00134472, Registered 23 August 2005) in the United States of America. In brief, inclusion criteria were as follows: age 15-69 years for both sexes and a Glasgow Coma Scale (GCS) score of 4-8. Written informed consent was obtained from legally authorized representatives of patients prior to inclusion. If informed consent could not be obtained within $2 \mathrm{~h}$ of admission, the consent policy was waived.

\section{Targeted temperature management (TTM)}

Treatments were performed as described in our original paper [15]. In brief, cooling was initiated within $2 \mathrm{~h}$ of the onset of TBI. The goal in each group was to achieve the targeted temperature within $6 \mathrm{~h}$ of the onset of TBI and to maintain this temperature for at least $72 \mathrm{~h}$, predominantly using surface cooling blankets. After $72 \mathrm{~h}$, the temperature was maintained at $<38{ }^{\circ} \mathrm{C}$ until 7 days after the onset of TBI.

\section{Definition of coagulopathy}

In previous literature, definitions of coagulopathy using the activated partial thromboplastin time (APTT) have varied from $32 \mathrm{~s}$ to $60 \mathrm{~s}[1,17]$. In the present study, we adopted the most severe APTT criteria (60 s). Accordingly, patients with an APTT $>60 \mathrm{~s}$ and/or an FDP level $>90 \mu \mathrm{g} / \mathrm{mL}$ on admission were allocated to the coagulopathy group [18-20].

\section{Patients}

In the original paper, 150 patients were randomly assigned (1:2 allocation ratio) to either the control group $\left(35.5-37.0{ }^{\circ} \mathrm{C}\right.$ ) or the MTH group $\left(32.0-34.0{ }^{\circ} \mathrm{C}\right)$, and analyzed by intention to treat analyses [15]. Per-protocol analyses were performed in 135 patients (control, 47 patients and MTH, 88 patients) [21]. In the present post hoc study, we re-evaluated these data $(n=135)$ based on initial coagulation markers, APTT, and/or FDP levels. Sixteen patients (control, 7 patients and MTH, 9 patients) were excluded as either APTT or FDP values were unavailable (Fig. 1). Patients were classified as either coagulopathy $(n=32,26.9 \%)$ or non-coagulopathy ( $n=87,73.1 \%)$. In patients with coagulopathy, 12 patients were allocated to the control group and 20 patients to the MTH group. In patients without coagulopathy, 28 were allocated to the control group and 59 patients were allocated to the MTH group.

\section{Data collection and study outcomes}

Data on the following parameters were collected: age, gender, systolic blood pressure, heart rate, GCS, unreactive pupil or pupils, platelet counts, APTT, fibrinogen, FDP, Traumatic Coma Data Bank classification, Injury Severity Score (ISS), Abbreviated ISS (AIS) for the head, AIS score $\geq 4$ for other organs on admission, complication rate during TTM, surgical intervention for TBI during administration, and favorable neurological outcomes and survival rates at 6 months following TBI. APTT and FDP levels in the acute phase (time to admission to day 3) were compared between the control and MTH groups with or without coagulopathy, respectively. Platelet counts in the acute phase (time to admission to day 3) were also compared between the control and MTH groups with coagulopathy.

The primary outcomes were favorable neurological outcomes, survival rates, and complication rates between 


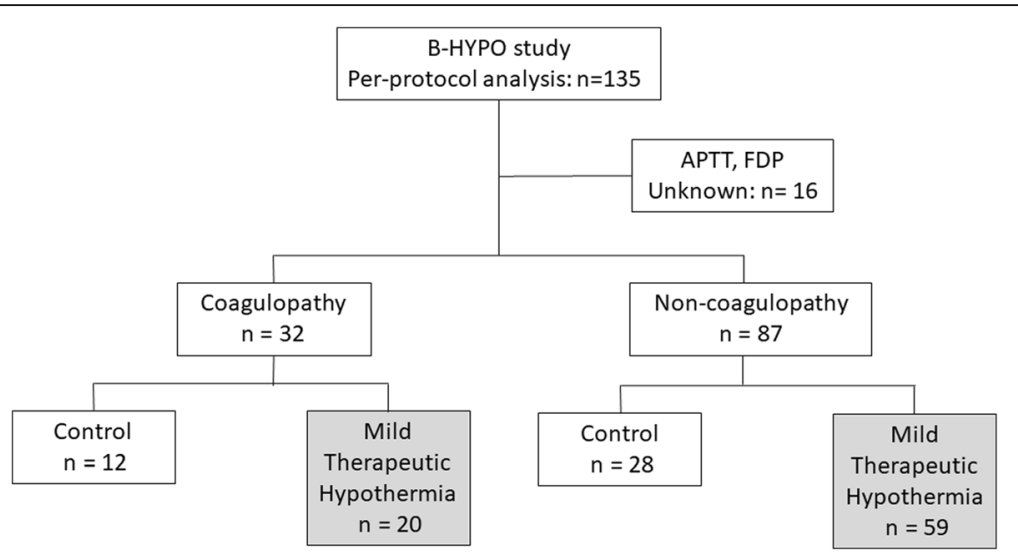

Fig. 1 Patient flow. APTT: activated partial thromboplastin time, FDP: fibrin/fibrinogen degradation products

coagulopathy and non-coagulopathy patients, and between the control and MTH groups with or without coagulopathy. The Glasgow Outcome Scale (GOS) at 6 months, was assessed by a neurosurgeon, a neurologist, or an emergency physician who was unaware of the patient's treatment. Good recovery and moderate disability according to the GOS scores at 6 months after injury were designated as a favorable neurological outcome. Fatal arrhythmia, thrombocytopenia, severe pneumonia, sepsis, and disseminated intravascular coagulation were defined as complications [22].

\section{Statistical analyses}

Baseline characteristics were compared between coagulopathy and the non-coagulopathy patients. Then, baseline characteristics, favorable neurological outcomes, and survival and complication rates were compared between the control $\left(35.5-37{ }^{\circ} \mathrm{C}\right)$ and $\mathrm{MTH}\left(32-34{ }^{\circ} \mathrm{C}\right)$ groups, with or without coagulopathy. Changes in APTT and FDP levels from admission to day 3 and ICP from day 1 to 1 day after rewarming were compared between the control and MTH groups with or without coagulopathy.

Continuous variables were analyzed using the MannWhitney $U$ test and categorical comparisons were performed using Fisher's exact test. Statistical analyses were performed using JMP version 11 software (SAS Institute, Cary, NC, USA). Results are presented as $\mathrm{n}(\%)$ or medians (interquartile ranges, IQRs). $P$-values $\leq 0.05$ were considered statistically significant.

\section{Results}

Comparison of baseline characteristics, neurological outcomes, survival rates, and complication rates between coagulopathy and non-coagulopathy patients

Coagulopathy occurred in $26.9 \%$ of included patients. No significant differences in baseline characteristics were observed between coagulopathy patients and noncoagulopathy patients, except for gender (Table 1). As expected, APTT in coagulopathy patients was significantly prolonged when compared to non-coagulopathy patients (median, IQR: $42.9 \mathrm{~s}$ [34.2-84.5] vs. $28.3 \mathrm{~s}$ [25.5-34.3], $P<0.01)$. The initial FDP in coagulopathy patients was significantly higher than that in noncoagulopathy patients $(114.8 \mu \mathrm{g} / \mathrm{mL}$ [92.5-168.3] vs. $30.9 \mu \mathrm{g} / \mathrm{mL}$ [14.2-50.3], $P<0.01)$.

Although no significant difference in favorable neurological outcome $(34.4 \%$ vs. $50.6 \%, P=0.15)$ and survival rates $(56.3 \%$ vs. $72.4 \%, P=0.12)$ was observed between coagulopathy and non-coagulopathy patients, these values were lower in coagulopathy patients. There was no difference between two groups in the complication rate $(P=0.85)$.

\section{Comparison of baseline characteristics between the control $\left(35.5-37^{\circ} \mathrm{C}\right)$ and MTH $\left(32-34^{\circ} \mathrm{C}\right)$ groups in the patients with or without coagulopathy}

No significant differences in patient characteristics were observed between the control and MTH groups among patients with or without coagulopathy (Table 2).

Comparison of neurological outcomes, survival rates and complication rates between the control and MTH groups in patients with or without coagulopathy

Among patients with coagulopathy, favorable neurological outcomes and survival rates were comparable between the control and MTH groups (33.3\% vs. $35.0 \%$, $P=1.00 ; 50.0 \%$ vs. $60.0 \%, P=0.72)$ with no difference in complication rates (Table 3 , left).

In patients without coagulopathy, the survival rate was significantly lower and the complication rate was significantly higher in the MTH group compared to the 
Table 1 Patient characteristics

\begin{tabular}{|c|c|c|c|}
\hline & $\begin{array}{l}\text { Coagulopathy } \\
n=32\end{array}$ & $\begin{array}{l}\text { Non-coagulopathy } \\
n=87\end{array}$ & $P$-value \\
\hline Age (years) & $42(22-56)$ & $42(21-55)$ & 0.55 \\
\hline Male & $27(87.1)$ & $52(61.1)$ & $<0.01$ \\
\hline Systolic blood pressure (mmHg) & $151(124-170)$ & $142(114-179)$ & 0.48 \\
\hline Heart rate (beats/min) & $83(71-110)$ & $86(70-106)$ & 0.89 \\
\hline Glasgow Coma Scale score & $6(4-7)$ & $6(4-7)$ & 0.60 \\
\hline Unreactive pupil or pupils & $14(43.8)$ & $37(42.5)$ & 1.00 \\
\hline Platelet counts $\left(\times 10^{4} / \mathrm{mm}^{3}\right)$ & $23.7(18.4-29.3)$ & $22.7(17.1-27.4)$ & 0.52 \\
\hline APTT (s) & $42.9(34.2-84.5)$ & $28.3(25.5-34.3)$ & $<0.01$ \\
\hline $\mathrm{FDP}(\mu \mathrm{g} / \mathrm{mL})$ & $114.8(92.5-168.3)$ & $30.9(14.2-50.3)$ & $<0.01$ \\
\hline Fibrinogen (mg/dL) & $206(140-267)$ & $202(165-243)$ & 0.87 \\
\hline TCDB classification & & & 0.77 \\
\hline Diffuse injury grade I & $0(0)$ & $2(2.3)$ & \\
\hline Diffuse injury grade II & $11(34.4)$ & $25(28.7)$ & \\
\hline Diffuse injury grade III & $7(21.9)$ & $12(13.8)$ & \\
\hline Diffuse injury grade IV & $1(3.1)$ & $3(3.5)$ & \\
\hline Non-evacuated mass/Evacuated mass & $1 / 12$ & $4 / 41$ & 0.68 \\
\hline Surgical operation for TBI & $16(51.6)$ & $58(66.7)$ & 0.19 \\
\hline Injury severity score & $25(21-34)$ & $25(17-30)$ & 0.09 \\
\hline AIS score for head & $4(4-5)$ & $4(4-5)$ & 0.16 \\
\hline Favorable outcome & $11(34.4)$ & $44(50.6)$ & 0.15 \\
\hline Survival rate & $18(56.3)$ & $63(72.4)$ & 0.12 \\
\hline Overall complication rate & $4(12.5)$ & $12(13.8)$ & 0.85 \\
\hline
\end{tabular}

Values are presented as $\mathrm{n}(\%)$ or median (interquartile ranges, IQRs)

MTH mild therapeutic hypothermia, AIS abbreviated injury score, TBI traumatic brain injury, CT computed tomography, FDP fibrin degradation products, TCDB Traumatic Coma Data Bank

control group $(89.3 \%$ vs. $64.4 \%, P=0.02$ and $0 \%$ vs. $20.3 \%, P<0.01$, respectively; Table 3 , right).

\section{Comparison of APTT and FDP levels between the fever control and MTH groups in patients with or without coagulopathy}

In patients with coagulopathy, there was no significant difference in APTT or FDP levels between the two groups at the time of admission; however, APTT was significantly prolonged in the MTH group compared to the control group on day 3 ( $P<0.05$; Fig. 2$)$.

In patients without coagulopathy, there was no significant difference in APTT or FDP levels between the two groups at the time of admission; however, FDP levels were significantly lower in the MTH group compared to the control group on day $1(P<0.05$; Fig. 2$)$.

\section{Comparison of platelet counts between the control and MTH groups in patients with coagulopathy}

In patients with coagulopathy, there were no significant differences in platelet counts between the two groups at the time of admission to 1 day after rewarming (Additional file 1).

\section{Comparison of ICP between the fever control and MTH groups in patients with or without coagulopathy}

In patients with coagulopathy, the median ICP was 20 (10-46) $\mathrm{mmHg}, 21$ (14-34) $\mathrm{mmHg}$, and 19 (13-37) $\mathrm{mmHg}$ on day 1 , day 3 , and 1 day after rewarming, respectively. In patients without coagulopathy, the median ICP was 15 (10-22) $\mathrm{mmHg}, 15$ (9-19) $\mathrm{mmHg}$, and 21 (16-33) $\mathrm{mmHg}$ on day 1 , day 3 , and 1 day after rewarming, respectively. ICP was significantly higher in patients with coagulopathy compared to patients without coagulopathy on day $3(p<0.01)$.

In patients with coagulopathy, ICP did not differ between the control and MTH groups on day 1 , day 3, or 1 day after rewarming (Fig. 3, left). In patients without coagulopathy, ICP was significantly lower in the MTH group compared to the control group on day 1 and at 1 day after rewarming (Fig. 3, right). 
Table 2 Comparison of patient characteristics

\begin{tabular}{|c|c|c|c|c|c|c|}
\hline \multirow[t]{2}{*}{ Variable } & \multicolumn{2}{|l|}{ Coagulopathy } & \multirow[b]{2}{*}{$P$-value } & \multicolumn{3}{|c|}{ Non-Coagulopathy } \\
\hline & $\begin{array}{l}\text { Control } \\
\left(35.5-37.0^{\circ} \mathrm{C}\right) \\
n=12\end{array}$ & $\begin{array}{l}\text { MTH } \\
\left(32.0-34.0^{\circ} \mathrm{C}\right) \\
n=20\end{array}$ & & $\begin{array}{l}\text { Control } \\
\left(35.5-37.0^{\circ} \mathrm{C}\right) \\
n=28\end{array}$ & $\begin{array}{l}\text { MTH } \\
\left(32.0-34.0^{\circ} \mathrm{C}\right) \\
n=59\end{array}$ & $P$-value \\
\hline Age (years) & $31(21-55)$ & $48(25-58)$ & 0.34 & $41(23-57)$ & $42(20-55)$ & 0.93 \\
\hline Male & $9(81.8)$ & $18(90.0)$ & 0.60 & $16(59.3)$ & $36(62.1)$ & 0.82 \\
\hline Systolic blood pressure (mmHg) & $162(128-177)$ & $138(122-160)$ & 0.15 & $142(115-183)$ & $143(110-175)$ & 0.88 \\
\hline Heart rate (beats/min) & $77(71-95)$ & $94(71-113)$ & 0.34 & $86(65-106)$ & $85(72-104)$ & 0.94 \\
\hline Glasgow Coma Scale score & $6(5-7)$ & $6(4-7)$ & 0.72 & $6(5-7)$ & $6(4-7)$ & 0.65 \\
\hline Unreactive pupil or pupils & $5(41.7)$ & $9(45.0)$ & 1.00 & $12(42.9)$ & $25(42.4)$ & 1.00 \\
\hline Platelet counts $\left(\times 10^{4} / \mathrm{mm}^{3}\right)$ & $22.4(18.7-29.3)$ & $24.5(16.8-29.2)$ & 0.91 & $26.2(16.7-29.8)$ & $22.1(17.1-26.2)$ & 0.14 \\
\hline APTT (s) & $42.8(27.3-81.9)$ & $44.9(35.4-87.1)$ & 0.73 & $27.4(24.3-36.2)$ & $28.9(25.7-33.2)$ & 0.58 \\
\hline $\mathrm{FDP}(\mu \mathrm{g} / \mathrm{mL})$ & $168(88.1-200.5)$ & $106(92.4-142.2)$ & 0.17 & $37.5(12.3-47.9)$ & $26(16.5-55.6)$ & 0.91 \\
\hline Fibrinogen (mg/dL) & $228(125-271)$ & $189(164-246)$ & 0.94 & $203(167-264)$ & $199(164-235)$ & 0.49 \\
\hline TCDB classification & & & 0.77 & & & 0.30 \\
\hline Diffuse injury grade I & $0(0)$ & $0(0)$ & & $1(3.6)$ & $1(1.7)$ & \\
\hline Diffuse injury grade II & $5(41.7)$ & $6(30.0)$ & & $8(28.6)$ & $17(28.8)$ & \\
\hline Diffuse injury grade III & $2(16.7)$ & $5(25.0)$ & & $6(21.4)$ & $6(10.2)$ & \\
\hline Diffuse injury grade IV & $0(0)$ & $1(5.0)$ & & $2(7.1)$ & $1(1.7)$ & \\
\hline Non-evacuated mass/Evacuated mass & $0 / 5$ & $1 / 7$ & 0.81 & $0 / 11$ & $4 / 30$ & 0.56 \\
\hline Surgical operation for TBI & $7(58.3)$ & $9(47.4)$ & 0.72 & $18(64.3)$ & $40(67.8)$ & 0.81 \\
\hline Injury severity score & $25(21-25)$ & $34(22-36)$ & 0.08 & $22(16-29)$ & $25(17-34)$ & 0.36 \\
\hline AIS score for head & $5(4-5)$ & $4(4-5)$ & 0.50 & $4(4-5)$ & $4(4-5)$ & 0.20 \\
\hline AIS score $\geq 4$ for other organs & $0(0)$ & $4(20.0)$ & 0.27 & $3(10.7)$ & $4(6.8)$ & 0.67 \\
\hline
\end{tabular}

Values are presented as $\mathrm{n}(\%)$ or median (interquartile ranges, IQRs)

MTH mild therapeutic hypothermia, AIS abbreviated injury score, TBI traumatic brain injury, $C T$ computed tomography, FDP fibrin degradation products, TCDB Traumatic Coma Data Bank

\section{Discussion}

In the present post hoc study, coagulopathy occurred in $32(26.9 \%)$ of 119 patients with severe TBI. In patients with coagulopathy, favorable neurological outcomes were recorded in one third of patients and their survival rate was greater than $50 \%$. Outcomes were similar between the MTH and control groups with no significant difference in complication rate, although prolongation of APTT lasted to day 3 in the MTH group. Consequently, we posit that both control and MTH have utility in the treatment of severe TBI in patients with coagulopathy on admission.

Tokutomi et al. examined the effects of hypothermia on several coagulation parameters (PT, APTT, platelet count, and AT-III) and performed a comparison with normothermia in TBI patients. They reported a trend toward a prolonged APTT in the hypothermia group on days 5 and $7(P=0.07$ and $P=0.06$, respectively). In the

Table 3 Comparison of neurological outcomes and complication rates between coagulopathic and non-coagulopathic patients, and between the MTH $\left(32-34{ }^{\circ} \mathrm{C}\right)$ and control $\left(35.5-37^{\circ} \mathrm{C}\right)$ groups with or without coagulopathy

\begin{tabular}{|c|c|c|c|c|c|c|}
\hline \multirow[t]{2}{*}{ Variable } & \multicolumn{3}{|l|}{$\begin{array}{l}\text { Coagulopathy } \\
n=32\end{array}$} & \multicolumn{2}{|l|}{$\begin{array}{l}\text { Non-Coagulopathy } \\
n=87\end{array}$} & \multirow[b]{2}{*}{$P$-value } \\
\hline & $\begin{array}{l}\text { Control }\left(35.5-37.0^{\circ} \mathrm{C}\right) \\
n=12\end{array}$ & $\begin{array}{l}\text { MTH } \\
\left(32.0-34.0^{\circ} \mathrm{C}\right) \\
n=20\end{array}$ & $P$-value & $\begin{array}{l}\text { Control }\left(35.5-37.0^{\circ} \mathrm{C}\right) \\
n=28\end{array}$ & $\begin{array}{l}\text { MTH } \\
\left(32.0-34.0^{\circ} \mathrm{C}\right) \\
n=59\end{array}$ & \\
\hline Favorable outcome & $4(33.3)$ & $7(35.0)$ & 1.00 & $16(57.1)$ & $28(47.5)$ & 0.49 \\
\hline Survival rate & $6(50.0)$ & $12(60.0)$ & 0.72 & $25(89.3)$ & $38(64.4)$ & 0.02 \\
\hline Overall complication rate & $1(8.3)$ & $3(15.0)$ & 1.00 & $0(0)$ & $12(20.3)$ & $<0.01$ \\
\hline
\end{tabular}

MTH mild therapeutic hypothermia

Neurological outcomes were evaluated 6 months after brain injury

Complications occurring during targeted temperature management were recorded 

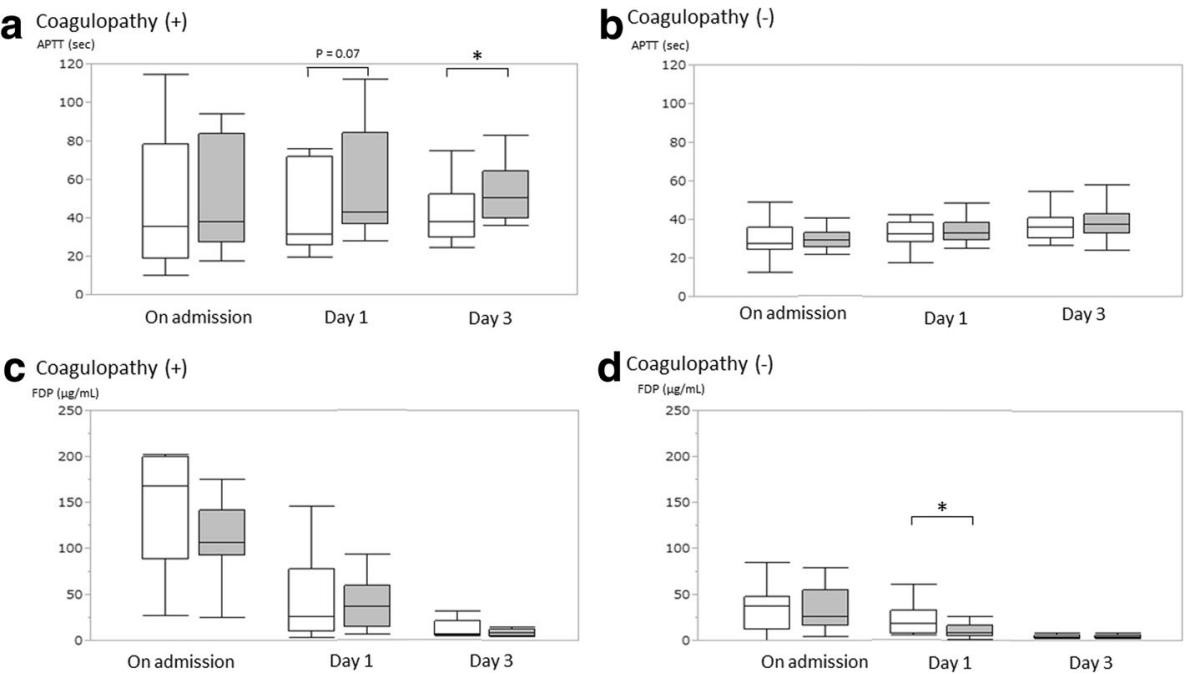

Fig. 2 Alterations of APTT and FDP between the fever control and MTH groups in patients with or without coagulopathy. a Comparisons of APTT between the control and the MTH groups in the patients with coagulopathy. $\mathbf{b}$ Comparisons of APTT between the control and the MTH groups in the patients without coagulopathy. c Comparisons of FDP between the control and the MTH groups in the patients with coagulopathy. d Comparisons of FDP between the control and the MTH groups in the patients without coagulopathy. The control group $\left(35.5^{\circ} \mathrm{C}-37^{\circ} \mathrm{C}\right)$ is indicated in white and the MTH group $\left(32^{\circ} \mathrm{C}-34^{\circ} \mathrm{C}\right)$ is indicated in gray. The boxes are the 25 th to 75 th percentiles and the whiskers are 5 th to 95th percentiles. ${ }^{*} p<0.05$; statistically significant. APTT: activated partial thromboplastin time, FDP: fibrin/fibrinogen degradation products

present study, the APTT in the MTH group at the time of admission (28.8 $\pm 2.7 \mathrm{~s})$ did not differ from that of the control group $(29.3 \pm 5.7$ s). Although the inclusion criterion used in the present study was a severely prolonged APTT of $>60 \mathrm{~s}$ [23], the APTT in the MTH group among patients with coagulopathy was comparable to Tokutomi's data and found to be significantly prolonged on day 3 compared to the control group [23].

Genet et al. examined the pathophysiology of traumainduced coagulopathy between isolated TBI and non-TBI patients, and concluded that hemostatic, vascular, and endothelial responses were comparable [24]. Theoretically, APTT indicates the activity of the intrinsic and common pathways of coagulation, and prolongation of the APTT indicates the presence of a coagulation disorder [25]. Among patients with coagulopathy included in the present study, APTT was prolonged in the MTH group compared to the fever control group and reached statistical significance on day 3 (Fig. 2a). These findings are attributable to the speed of decreased biochemical reactions due to the decreased core body temperature in the MTH group. A similar trend was observed in patients without coagulopathy; however, this difference did not reach statistical significance (Fig. 2b). On the other hand, FDP levels in patients with coagulopathy were markedly elevated at the time of admission, as expected (Fig. 2c). The elevation
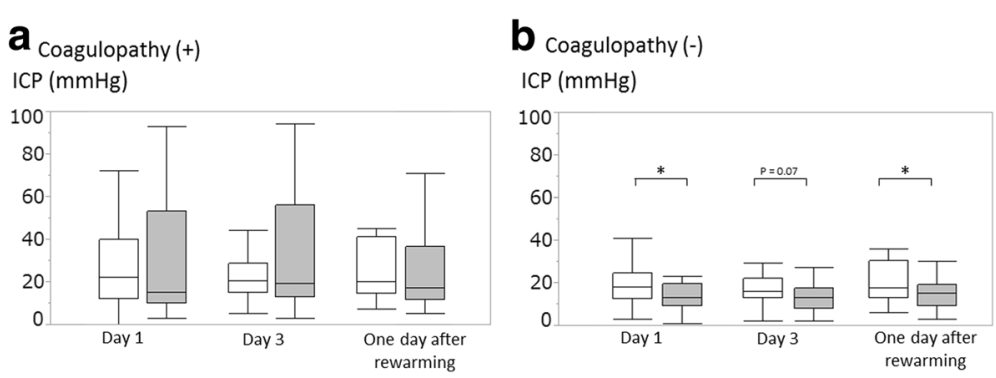

Fig. 3 Alterations of ICP between the control and MTH groups in patients with or without coagulopathy. a Comparisons of ICP between the control and the MTH groups in the patients with coagulopathy. $\mathbf{b}$ Comparisons of ICP between the control and the MTH groups in the patients without coagulopathy. The control $\left(35.5-37^{\circ} \mathrm{C}\right)$ group is indicated in white and the MTH $\left(32-34{ }^{\circ} \mathrm{C}\right)$ group is indicated in gray. The boxes are the 25th to 75 th percentiles and the whiskers are 5 th to 95 th percentiles. ${ }^{*} p<0.05$; statistically significant 
indicated acceleration of systemic fibrin deposition and secondary fibrinolysis/fibrinogenolysis by plasmin [24]. The values gradually decreased until day 3 , both in the control and MTH groups, without statistical significance.

Polderman reported that very mild hypothermia $\left(35^{\circ} \mathrm{C}\right)$ does not affect coagulation and can be safely used even in patients at high risk of bleeding [9]. In addition, regarding mild hypothermia $\left(33-35{ }^{\circ} \mathrm{C}\right)$, Wolberg et al. examined healthy volunteers and found that enzyme activities and platelet activation were not reduced at $33^{\circ} \mathrm{C}$ [26]. Therefore, Gando et al. posited that isolated mild hypothermia at 33 to $35{ }^{\circ} \mathrm{C}$ does not have severe effects on hemostasis in typical clinical trauma settings [27]. Based on our study, MTH did not seem to negatively affect the outcomes in patients with coagulopathy following severe TBI on admission; therefore, the present study indicates that MTH may be applicable even in patients with severe TBI and coagulopathy. Typically, TBI-associated coagulopathy is not related to visual blood loss [28]; therefore, clinicians should attend to intracranial hemorrhage and organs with ongoing bleeding. In fact, patients with an AIS score $\geq 3$ for other organs treated with mild therapeutic hypothermia had a mortality rate greater than $80 \%$ in the present study (data not shown).

In the patients with coagulopathy, ICP tended to be high with wide ranges both in the control and the MTH groups, compared to those in the patients without coagulopathy during the periods of the targeted temperature managements, day 1 and day 3 (Fig. 3a, b). These differences might contribute their low rates of favorable neurological outcome and survival both in the fever control and MTH groups with coagulopathy (Table 3).

There are several limitations to the present study. First, the original study was terminated before the full sample size had been recruited. Additionally, the sample size was further reduced from 150 to 119 patients as APTT and/or FDP values could not be obtained in 16 out of 135 patients. These factors may have biased the outcomes of the present study. Second, d-dimer levels are the most specific test for coagulopathy in TBI [29]; however, the number of patients with $d-$ dimer levels measured at the time of arrival was small in the present study. Further, PT could not be examined due to unavailability of the dataset. Third, an extremely small number of patients were included in this study (coagulopathy occurred in only 32 patients), and the results require confirmation in a larger cohort. Beta-error may have also existed. Fourth, although there was no significant difference in age $(p=0.34)$, patients in fever control group were younger than those in MTH group (median age 31 years vs. 48 years). Therefore, additional studies adjusted for background factors will be required. Finally, as the present study was a post hoc subanalysis, selection bias may have been present.

\section{Conclusion}

Our study suggests that in comparison to control, MTH does not worsen the outcome of patients with coagulopathy following severe TBI.

\section{Additional file}

Additional file 1: Comparison of platelet counts between the control and MTH groups in patients with coagulopathy. MTH, mild therapeutic hypothermia. Values are presented as median (interquartile ranges, IQRs). (DOCX $13 \mathrm{~kb})$

\section{Abbreviations \\ AIS: Abbreviated Injury Severity Score; APTT: activated partial thromboplastin time; B-HYPO: Brain Hypothermia study group; FDP: fibrin/fibrinogen degradation products; GCS: Glasgow Coma Scale; ICP: intracranial pressure; ISS: Injury Severity Score; MTH: mild therapeutic hypothermia; RCT: randomized controlled trial; TBI: traumatic brain injury; TTM: targeted temperature management}

\section{Acknowledgments}

Not applicable.

\section{Funding}

This study was supported by research project grants from the Japanese Ministry of Health, Labour and Welfare (H-14-shinkin-005, H-15-shinkin-001, and H-16-shinkin-001) and by the Japanese Human Science Association, 2002-2004.

\section{Availability of data and materials}

The datasets used in the current study are available from the corresponding author on reasonable request.

\section{Authors' contributions}

TH planned and conducted the statistical analyses on the database, appraised the background literature, prepared the first draft of the manuscript, and coordinated subsequent revisions. KK, SY, and KD contributed to collect the data. YK, YO and TM contributed to planning the analyses and to drafting and reviewing the manuscript. All authors read and approved the final manuscript and agree to be accountable for all aspects of the work.

Ethics approval and consent to participate

The protocol was approved by the Institutional Review Board of each participating hospital.

\section{Consent for publication}

Not applicable.

\section{Competing interests}

The authors declare that they have no competing interests.

\section{Publisher's Note}

Springer Nature remains neutral with regard to jurisdictional claims in published maps and institutional affiliations.

\section{Author details}

'Department of Emergency, Disaster and Critical Care Medicine, Kagawa University Hospital, 1750-1 Ikenobe, Miki, Kita, Kagawa 761-0793, Japan.

${ }^{2}$ Department of Emergency Medicine, Tokuyama Central Hospital, 1-1 Kouda, Shunan, Yamaguchi 745-8522, Japan. ${ }^{3}$ Advanced Medical Emergency and Critical Care Center, Yamaguchi University School of Medicine, 1-1-1 Minami 
Kogushi, Ube, Yamaguchi 755-8505, Japan. ${ }^{4}$ Department of Emergency Medicine, School of Medicine, Showa University, 1-5-8 Hatanodai, Shinagawaku, Tokyo 142-8666, Japan. ${ }^{5}$ Yamaguchi Prefectural Grand Medical Center, 77 Osaki, Boufu, Yamaguchi 747-8511, Japan. ${ }^{6}$ Department of Emergency, Disaster and Critical Care Medicine, 1750-1 Ikenobe, Miki, Kita, Kagawa 761-0793, Japan.

Received: 6 July 2017 Accepted: 11 December 2017

Published online: 20 December 2017

\section{References}

1. Epstein DS, Mitra B, O'Reilly G, Rosenfeld JV, Cameron PA. Acute traumatic coagulopathy in the setting of isolated traumatic brain injury: a systematic review and meta-analysis. Injury. 2014;45(5):819-24.

2. Harhangi BS, Kompanje EJ, Leebeek FW, Maas Al. Coagulation disorders after traumatic brain injury. Acta Neurochir. 2008;150(2):165-75. discussion 175

3. Lustenberger T, Talving P, Kobayashi L, Barmparas G, Inaba K, Lam L, Branco BC, Demetriades D. Early coagulopathy after isolated severe traumatic brain injury: relationship with hypoperfusion challenged. J Trauma. 2010;69(6):1410-4

4. Talving P, Benfield R, Hadjizacharia P, Inaba K, Chan LS, Demetriades D. Coagulopathy in severe traumatic brain injury: a prospective study. J Trauma. 2009;66(1):55-61. discussion 61-52

5. Wafaisade A, Lefering $R$, Tjardes $T$, Wutzler $S$, Simanski $C$, Paffrath $T$, Fischer P, Bouillon B, Maegele M, Trauma Registry of DGU. Acute coagulopathy in isolated blunt traumatic brain injury. Neurocrit Care. 2010;12(2):211-9.

6. Chhabra G, Rangarajan K, Subramanian A, Agrawal D, Sharma S, Mukhopadhayay AK. Hypofibrinogenemia in isolated traumatic brain injury in Indian patients. Neurol India. 2010;58(5):756-7.

7. Kearney TJ, Bentt L, Grode M, Lee S, Hiatt JR, Shabot MM. Coagulopathy and catecholamines in severe head injury. J Trauma. 1992;32(5):608-11. discussion 611-602

8. Endo A, Shiraishi A, Otomo Y, Kushimoto S, Saitoh D, Hayakawa M, Ogura H, Murata K, Hagiwara A, Sasaki J, et al. Development of novel criteria of the "lethal triad" as an indicator of decision making in current trauma care: a retrospective multicenter observational study in Japan. Crit Care Med. 2016;44(9):e797-803.

9. Polderman $\mathrm{KH}$. Mechanisms of action, physiological effects, and complications of hypothermia. Crit Care Med. 2009;37(7 Suppl):S186-202.

10. Polderman $\mathrm{KH}$, Herold I. Therapeutic hypothermia and controlled normothermia in the intensive care unit: practical considerations, side effects, and cooling methods. Crit Care Med. 2009;37(3):1101-20.

11. Clifton GL, Miller ER, Choi SC, Levin HS, McCauley S, Smith KR Jr, Muizelaar JP, Wagner FC Jr, Marion DW, Luerssen TG, et al. Lack of effect of induction of hypothermia after acute brain injury. N Engl J Med. 2001;344(8):556-63.

12. Clifton GL, Valadka A, Zygun D, Coffey CS, Drever P, Fourwinds S, Janis LS, Wilde $E$, Taylor P, Harshman K, et al. Very early hypothermia induction in patients with severe brain injury (the National Acute Brain Injury Study: hypothermia II): a randomised trial. Lancet Neurol. 2011;10(2):131-9.

13. Hutchison JS, Ward RE, Lacroix J, Hebert PC, Barnes MA, Bohn DJ, Dirks PB, Doucette S, Fergusson D, Gottesman R, et al. Hypothermia therapy after traumatic brain injury in children. N Engl J Med. 2008;358(23):2447-56.

14. Cariou A, Payen JF, Asehnoune K, Audibert G, Botte A, Brissaud O, Debaty G, Deltour S, Deye N, Engrand N et al: Targeted temperature management in the ICU: Guidelines from a French expert panel. Anaesth Crit Care Pain Med. 2017.

15. Maekawa T, Yamashita S, Nagao S, Hayashi N, Ohashi Y. Prolonged mild therapeutic hypothermia versus fever control with tight hemodynamic monitoring and slow rewarming in patients with severe traumatic brain injury: a randomized controlled trial. J Neurotrauma. 2015;32(7):422-9.

16. Andrews PJ, Sinclair HL, Rodriguez A, Harris BA, Battison CG, Rhodes JK, Murray GD. Hypothermia for intracranial hypertension after traumatic brain injury. N Engl J Med. 2015;373(25):2403-12.

17. Chang EF, Meeker M, Holland MC. Acute traumatic intraparenchymal hemorrhage: risk factors for progression in the early post-injury period. Neurosurgery. 2006;58(4):647-56. discussion 647-656

18. Brohi K, Cohen MJ, Davenport RA. Acute coagulopathy of trauma: mechanism, identification and effect. Curr Opin Crit Care. 2007;13(6):680-5.
19. Brohi K, Cohen MJ, Ganter MT, Matthay MA, Mackersie RC, Pittet JF. Acute traumatic coagulopathy: initiated by hypoperfusion: modulated through the protein C pathway? Ann Surg. 2007;245(5):812-8.

20. Brohi K, Singh J, Heron M, Coats T. Acute traumatic coagulopathy. J Trauma. 2003;54(6):1127-30.

21. Hifumi T, Kuroda Y, Kawakita K, Yamashita S, Oda Y, Dohi K, Maekawa T. Fever control management is preferable to mild therapeutic hypothermia in traumatic brain injury patients with abbreviated injury scale 3-4: a multicenter, randomized controlled trial. J Neurotrauma. 2016;33(11):1047-53.

22. Sawamura A, Gando S, Hayakawa M, Hoshino H, Kubota N, Sugano M. Effects of antithrombin III in patients with disseminated intravascular coagulation diagnosed by newly developed diagnostic criteria for critical illness. Clin Appl Thromb Hemost. 2009;15(5):561-6.

23. Tokutomi T, Miyagi T, Morimoto K, Karukaya T, Shigemori M. Effect of hypothermia on serum electrolyte, inflammation, coagulation, and nutritional parameters in patients with severe traumatic brain injury. Neurocrit Care. 2004;1(2):171-82.

24. Sawamura A, Hayakawa M, Gando S, Kubota N, Sugano M, Wada T, Katabami K. Disseminated intravascular coagulation with a fibrinolytic phenotype at an early phase of trauma predicts mortality. Thromb Res. 2009;124(5):608-13.

25. Poller L. Standardization of the APTT test. Current status. Scand J Haematol Suppl. 1980;37:49-63.

26. Wolberg AS, Meng ZH, Monroe DM 3rd, Hoffman M. A systematic evaluation of the effect of temperature on coagulation enzyme activity and platelet function. J Trauma. 2004;56(6):1221-8.

27. Gando S, Sawamura A, Hayakawa M. Trauma, shock, and disseminated intravascular coagulation: lessons from the classical literature. Ann Surg. 2011;254(1):10-9.

28. Sawamura A, Hayakawa M, Gando S, Kubota N, Sugano M, Wada T, Katabami K. Application of the Japanese Association for Acute Medicine disseminated intravascular coagulation diagnostic criteria for patients at an early phase of trauma. Thromb Res. 2009;124(6):706-10.

29. Zhang D, Gong S, Jin H, Wang J, Sheng P, Zou W, Dong Y, Hou L. Coagulation parameters and risk of progressive hemorrhagic injury after traumatic brain injury: a systematic review and meta-analysis. Biomed Res Int. 2015;2015:261825.

\section{Submit your next manuscript to BioMed Central and we will help you at every step:}

- We accept pre-submission inquiries

- Our selector tool helps you to find the most relevant journal

- We provide round the clock customer support

- Convenient online submission

- Thorough peer review

- Inclusion in PubMed and all major indexing services

- Maximum visibility for your research

Submit your manuscript at www.biomedcentral.com/submit
Biomed Central 